Bundesgesundheitsbl -

Gesundheitsforsch - Gesundheitsschutz

2002 $\cdot 45: 113-122 \odot$ Springer-Verlag 2002

Leitthema: Stammzellen

H. Rohdewohld ${ }^{1} \cdot$ A. M. Wobus ${ }^{2}$

${ }^{1}$ Robert Koch-Institut

2 Institut für Pflanzengenetik und Kulturpflanzenforschung, Gatersleben

\title{
Embryonale Stammzellen der Maus
}

\section{Eigenschaften, Potenzial und Verwendung}

\author{
Schlüsselwörter \\ ES-Zellen · EG-Zellen · Maus · \\ Stammzelldifferenzierung
}

Stammzellen (ES-Zellen) gegenwärtig ge-

schenkt wird, resultiert aus ihrer Fähigkeit,

unter geeigneten Bedingungen in der

Zellkultur zahlreiche Zelltypen bilden zu

können. Hierauf basiert die Hoffnung, aus

embryonalen Stammzellen Spenderzellen

für Gewebeersatz gewinnen zu können. Der

vorliegende Beitrag befasst sich mit den

embryonalen Stammzellen der Maus (muri-

ne ES-Zellen), da an innen in den letzten

Jahrzehnten die grundlegenden Erkenntnisse über die Eigenschaften und das Potenzial embryonaler Stammzellen gewonnen wurden. Murine ES-Zellen finden in der Grundlagenforschung und in der medizinischen Forschung vielfache Anwendungen. Sie kommen z. B.zum Einsatz, um mit ihrer Hilfe gezielte genetische Veränderungen in Mäuse einzubringen und an den Tieren (so genannten Kock-out-Mäusen) den Einfluss definierter Genfunktionen auf Entwicklungs- und Krankheitsprozesse zu studieren. ES-Zellen der Maus können aber auch in der Zellkultur (in vitro) in zahlreiche Zelltypen differenzieren und dienen als Modellsysteme zur Untersuchung des Entwicklungspotenzials embryonaler Stammzellen. Es wurden z. B. Protokolle zur Differenzierung von ES-Zellen in kardiale, myogene, neurale, adipogene, hämatopoetische, endotheliale, chondrogene oder vaskuläre glatte Muskelzellen etabliert. Die Arbeit mit ES-Zellen der Maus hat zudem gezeigt, dass sich embryonale Stammzellen zur Analyse der Wirkung embryotoxischer und pharmakologischer Substanzen eignen. er Begriff „Stammzellen“ eint eine Vielzahl von Zellen unterschiedlichster Herkunft. Allen diesen Zellen gemeinsam sind jedoch zwei grundsätzliche Eigenschaften: Stammzellen befinden sich im Gegensatz zu den hoch spezialisierten Zellen im erwachsenen Organismus in einem undifferenzierten (unspezialisierten) Zustand und können sich unter bestimmten Bedingungen im Körper (in vivo) und teilweise in der Zellkultur (in vitro) teilen und vermehren, ohne diese Eigenschaft zu verlieren. Zudem besitzen sie das Potenzial, zu Zellen unterschiedlichster Funktion auszureifen, das heißt in spezialisierte Zelltypen zu differenzieren.

Entsprechend ihrer Herkunft werden embryonale Stammzellen (ES-Zellen), embryonale Keimzellen (EG-Zellen) sowie Stammzellen aus fötalem und erwachsenem Körpergewebe (gewebespezifische fötale oder adulte somatische Stammzellen) unterschieden. ES-Zellen werden aus frühen embryonalen Entwicklungsstadien gewonnen. EG-Zellen entstammen den so genannten primordialen Keimzellen (PG-Zellen), die sich in der fötalen Keimdrüsenleiste finden und aus denen sich später die Gameten, das heißt die Ei- oder Samenzellen entwickeln. Somatische Stammzellen sind unspezialisierte Zellen, die sich in bestimmten Organen des Fötus oder des erwachsenen Organismus finden. Die oben genannten Eigenschaften der Stammzellen sind in ES-Zellen, EG-Zellen sowie in somatischen Stammzellen in unterschiedlichem Maße ausgeprägt. Undifferenzierte ES- und EG-Zellen der Maus können sich z. B. in der Zellkultur unbegrenzt teilen und vermehren, während dieses für adulte somatische Stammzellen meist nur über begrenzte Zeiträume möglich ist. Letztere können in der Zellkultur relativ schnell ihren undifferenzierten Zustand verlieren. Zudem besitzen ES- und EG-Zellen das Potenzial, sich in Körperzellen jeden Typs zu differenzieren, während diese Fähigkeit adulten somatischen Stammzellen offenbar nicht gegeben ist, das heißt diese Zellen besitzen ein eingeschränktes Entwicklungspotenzial.

Über die Eigenschaften und das Potenzial verschiedener adulter somatischer Stammzellen wird ausführlich in mehreren Beiträgen des vorliegenden Heftes berichtet. In diesem Artikel soll hingegen auf die Charakteristika von ES- und EG-Zellen der Maus eingegan-

Priv.-Doz.Dr. Anna M. Wobus

Institut für Pflanzengenetik und Kulturpflanzenforschung (IPK),

Corrensstraße 3,06466 Gatersleben,

E-Mail:wobusam@ipk-gatersleben.de 
Bundesgesundheitsbl -

Gesundheitsforsch - Gesundheitsschutz

2002 • 45:113-122 @ Springer-Verlag 2002

\section{H. Rohdewohld · A. M. Wobus}

Mouse Embryonic Stem Cells.

Properties, Potential, and Applications

\section{Abstract}

During the last few years research on embryonic stem cells has received much public attention due to the fact that these cells are able to differentiate in vitro into many specialized cells and thus may serve as a source for a variety of tissues. The following article focuses on mouse embryonic stem cells (murine ES cells), because research on these cells has given insight into the potential of embryonic stem cells. Murine ES cells are permanent cell lines established from the inner cell mass (ICM) of early embryos (blastocysts). ES cells are undifferentiated pluripotent cells that are able to undergo an unlimited number of cell divisions without loosing the undifferentiated phenotype. The same is true for mouse primordial germ cell lines (murine EG cell lines), that where established from the fetal progenitor cells of primordial germ cells. Mouse embryonic stem cells are used for different purposes. In basic research they are used to study the consequences of mutations within genes that control embryonic development and/or the development of diseases. Because of their ability to differentiate into a variety of specialized cell types, murine ES cells also serve as model systems to establish specific differentiation protocols. In the last few years protocols were established for the in vitro development of undifferentiated embryonic stem cells into differentiated cardiac, skeletal muscle, neural, adipogenic, haematopoietic, endothelial, chondrogenic or vascular smooth muscle cells. Last but not least, studies on mouse ES cells have demonstrated that embryonic cells and their differentiated derivatives can be used to analyse the effects of toxic substances or of pharmaceutical drugs.

\section{Keywords}

ES cells $\cdot$ PG cells $\cdot$ Mouse .

Stem cell differentiation

\section{Leitthema: Stammzellen}

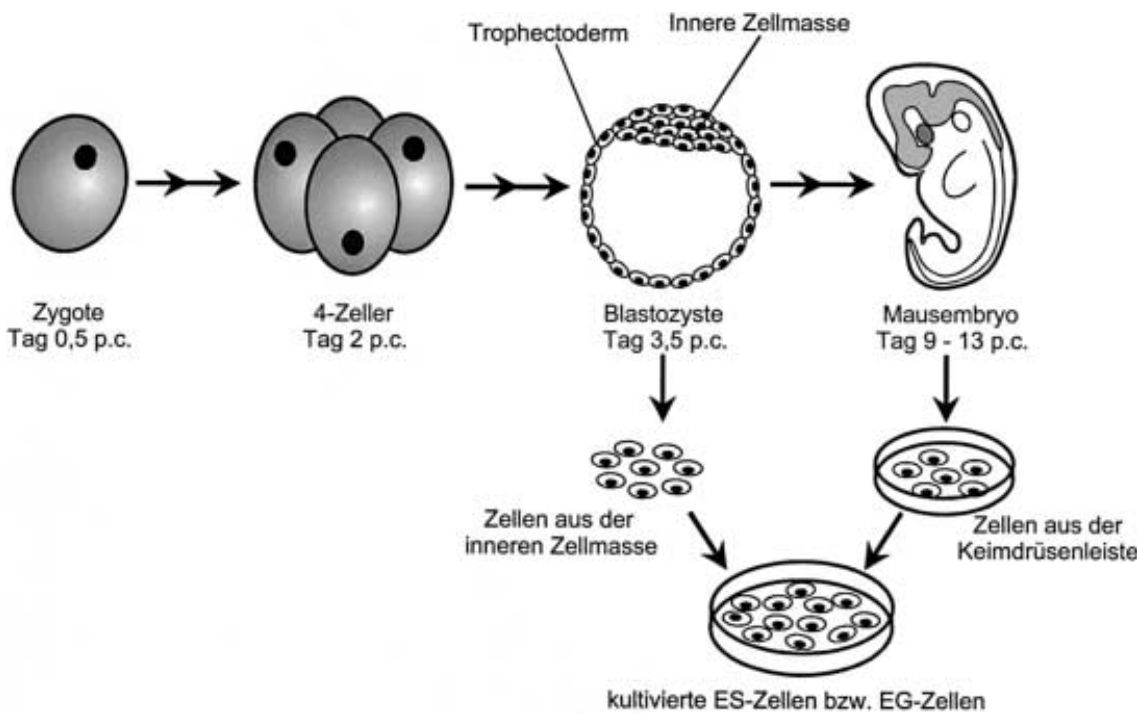

Abb. $1 \Delta$ Schematische Darstellung der frühen Embryonalentwicklung der Maus und der Gewinnung von ES-Zelllinien bzw. EG-Zelllinien. Eine detaillierte Beschreibung findet sich in dem Unter-Kapitel „ES- und EG-Zellen der Maus: Definitionen und Herkunft" (P.c. post coitum, ES-Zellen Embryonale Stammzellen, EG-Zellen Embryonale Keimzellen)

gen werden. Dargelegt werden die Methoden zu ihrer Gewinnung, ihre Eigenschaften sowie die Erkenntnisse über ihr Potenzial und die mögliche Übertragbarkeit dieser Erkenntnisse auf menschliche embryonale Stammzellen. Kurz werden auch die bisher bekannten Unterschiede zwischen ES-Zellen der Maus und humanen ES-Zellen dargestellt. Letztere werden jedoch ausführlich in dem Beitrag von M. Pera in diesem Heft diskutiert.

\section{ES- und EG-Zellen der Maus: Definitionen und Herkunft}

\section{ES-Zellen der Maus}

Für das Verständnis der Herkunft embryonaler Stammzellen ist die Kenntnis der frühen Embryonalentwicklung erforderlich (Abb.1). Nach der Verschmelzung von Ei- und Samenzellen und der Vereinigung der Vorkerne durchläuft die befruchtete Eizelle (Zygote) eine Reihe von Zellteilungen: Über das Zwei-, Vierund Acht-Zellstadium wird bei der Maus am Tag 2,5 der Entwicklung das so genannte Morula-Stadium (16-Zellstadium) und schließlich nach etwa 3,5 Tagen das Blastozystenstadium, das ca.15o Zellen umfasst, erreicht. Die Blastozyste besteht aus den Zellen der Inneren Zellmasse (ICM, Embryoblast), der Blastocoelhöhle sowie den äußeren Trophoblastenzellen (Trophectoderm). Blas- tozysten lassen sich bei Mäusen aus dem Uterus herausspülen.

ES-Zellen der Maus (murine ESZellen) werden aus der Inneren Zellmasse von Blastozysten gewonnen. Ihre Isolierung gelang erstmals $\mathrm{zu}$ Beginn der 8oer-Jahre $[1,2]$ und war ein großer Durchbruch für die Entwicklungs- und Zellbiologie. Zur Gewinnung von ESZellen werden die Blastozysten unter definierten Bedingungen in die Zellkultur überführt. Hier wachsen die Zellen der Inneren Zellmasse als undifferenzierte Zellen aus. Um den undifferenzierten Entwicklungszustand der ES-Zellen zu erhalten, erfolgt ihre Kultivierung auf einem speziellen Nährrasen, dem „FeederLayer", aus mitotisch inaktivierten embryonalen Mausfibroblasten (MEF-Zellen) oder alternativ in Anwesenheit von Differenzierungshemmfaktoren wie dem „Leukemia-Inhibitory-Faktor (LIF)“, der von den MEF-Zellen abgegeben wird.

\section{„ES-Zelllinien lassen sich nahe- zu unbegrenzt im undifferen- zierten Zustand halten."}

Die Kultivierung embryonaler Stammzellen gelingt relativ leicht aus bestimmten Stämmen der Maus, z. B. dem Stamm 129. Wesentlich unzuverlässiger gelingt die Etablierung von ES-Zelllinien aus anderen Stämmen, z. B. C57BL6 oder 
Balb/c. Die ES-Zelllinien der Maus lassen sich nahezu unbegrenzt im undifferenzierten Zustand kultivieren. So zeigen z. B. Zelllinien, die über zwei Jahre oder mehr in Kultur gehalten wurden und mehrere hundert Zellteilungen durchlaufen haben, keinen Verlust ihres undifferenzierten Zustandes. auch weisen sie keine Veränderungen des normalen diploiden Chromosomensatzes auf, das heißt ihr Karyotyp bleibt stabil [3]. ES-Zelllinien der Maus können auch über lange Zeiträume tiefgefroren aufbewahrt werden. Heute werden daher 90\% der Forschungsarbeiten mit nur fünf etablierten Stammzelllinien der Maus durchgeführt.

In diesem Zusammenhang soll darauf hingewiesen werden, dass es bis heute nur bei drei Säugern, nämlich bei Maus, Affen (Rhesusaffe) und dem Menschen gelungen ist, embryonale Stammzellen in Kultur zu nehmen und zu vermehren, das heißt ES-Zelllinien zu erzeugen $[4,5,6,7]$. Dies zeigt, dass das Verfahren zur Etablierung dieser Stammzellen hoch aufwendig ist und dass weiterhin Forschungsbedarf auf diesem Gebiet besteht.

\section{EG-Zellen der Maus}

Embryonale Keimzellen (EG-Zellen) werden, im Vergleich zu ES-Zellen, einem späteren Entwicklungsstadium der Maus entnommen (Abb. 1). EG-Zellen können aus den Vorläuferzellen von Eiund Samenzellen, den primordialen Keimzellen (PG-Zellen), gewonnen werden. Letztere lassen sich wiederum aus den Keimdrüsenleisten (Genitalleisten) neun bis 13 Tage alter Mausembryonen isolieren und können anschließend in Kultur genommen werden. Die Etablierung undifferenzierter embryonaler Keimzelllinien (EG-Zelllinien) aus der Maus gelang erstmals Anfang der 9oerJahre $[8,9]$. Dieses Verfahren wurde nicht bewusst als Alternative zur Herstellung von ES-Zelllinien entwickelt. Vielmehr entsprang es der Suche der Wissenschaftler nach Möglichkeiten, Vorläuferzellen der Keimzellen zu kultivieren, um diese leichter untersuchen $\mathrm{zu}$ können. EG-Zellen der Maus sind den ES-Zellen nicht gleichzusetzen. Sie haben mit ihnen zwar zahlreiche Eigenschaften gemein, unterscheiden sich jedoch auf molekularer Ebene und besitzen daher vermutlich ein eingeschränk- teres Entwicklungspotenzial (siehe Kapitel „Eigenschaften von EG-Zellen der Maus").

\section{ES- und EG-Zellen der Maus: Eigenschaften}

\section{Totipotenz und Pluripotenz}

Totipotente undifferenzierte Zellen sind Zellen, die in der Lage sind, alle Gewebe eines sich entwickelnden Organismus zu bilden, einschließlich der Zellen, die nicht Teil des Embryos sind, wie die Plazenta. Totipotente Zellen besitzen also die Fähigkeit, nach Übertragung in den Uterus zu einem vollständigen Organismus heranzureifen. Diese Zellen sind nur in frühen Embryonalstadien und in sehr geringer Anzahl vorhanden. So sind bei der Maus nur die befruchteten Eizellen (Zygoten) und die Zellen des embryonalen Zwei- bis Acht-Zellstadiums (Blastomere) totipotent. Nach dem Morula-Stadium verlieren die embryonalen Zellen infolge der Differenzierung in innere (Innere Zellmasse) und äußere Zellen (Trophoblastenzellen) ihre Totipotenz. ES-Zellen sind „nur noch“ "pluripotente Zellen. Sie entstammen der Inneren Zellmasse, die den prospektiven Embryo bildet, aber nicht die zur Entwicklung erforderlichen extraembryonalen Gewebe. ES-Zellen können alle Gewebe des Organismus einschließlich der Keimzellen bilden, sind aber allein nicht mehr in der Lage, einen kompletten Organismus $\mathrm{zu}$ generieren. Pluripotent sind auch die primordialen Keimzellen (PG-Zellen) und damit die aus ihnen abgeleiteten EG-Zelllinien.

Die Pluripotenz von ES-Zelllinien der Maus lässt sich mit Hilfe von drei Experimenten demonstrieren $[3,10,11]$. Werden ES-Zellen in die Innere Zellmasse von Blastozysten einer Maus übertragen und diese Blastozysten dann in den Uterus von Mäusen überführt, beteiligen sich die ES-Zellen an der Bildung aller Gewebe des sich entwickelnden Embryos. Sie sind damit in der Lage, Zellen aller drei Keimblätter (Ektoderm, Endoderm, Mesoderm) zu bilden, das heißt sich in vivo in alle Zelltypen zu differenzieren. Das resultierende Tier trägt damit in allen Organen neben den Zellen, die sich aus der Ursprungsblastozyste entwickelt haben, auch Zellen der übertragenen ES-Zellen. Das Tier ist also eine so genannte Chimäre.
Eine zweite Methode zum Nachweis der Pluripotenz von ES-Zelllinien ist ihre Injektion in erwachsene immunsupprimierte Mäuse. Die Injektion der Zellen erfolgt unter die Haut oder in die Nierenkapsel. Sind die Zellen pluripotent, entwickeln sich in den Tieren benigne Tumore, d.h. Teratome. Diese Tumore enthalten die unterschiedlichsten Zelltypen (z. B. neuronale Gewebe, Knochen-Knorpel-Gewebe, Skelettmuskulatur etc), was wiederum die Fähigkeit von ES-Zellen demonstriert, in vivo in die unterschiedlichsten Zellen differenzieren zu können.

Die Pluripotenz von ES-Zellen zeigt sich drittens auch in ihrer Fähigkeit, in der Zellkultur, also in vitro, spontan oder induziert in spezialisierte Zelltypen differenzieren zu können. Auf diese und die zuerst genannte Eigenschaft wird im Folgenden näher eingegangen.

\section{Eigenschaften von ES-Zellen der Maus}

\section{In-vitro-Differenzierungspotenzial muriner ES-Zellen}

Wie bereits erwähnt, besitzen ES-Zelllinien der Maus die Fähigkeit, sich nahezu unbegrenzt in Zellkultur (in vitro) zu vermehren und sich dort auch in fast alle Zellen des Körpers entwickeln (differenzieren) zu können.

Um in der Zellkultur eine Entwicklung in verschiedene Zellen zu induzieren, wird den kultivierten ES-Zellen zunächst der „Feeder-Layer“ bzw. das LIF entzogen. Dieses führt dazu, dass sich die Zellen in Form von Zellverbänden aggregieren und mit einer spontanen Differenzierung beginnen. Die Zellverbände werden auch als „Embryoidkörper" (embryoid-bodies) bezeichnet. Diese Bezeichnung ist insofern irreführend, als Embryoidkörper keine Verwandtschaft zu Embryonen aufweisen und sich auch nicht in Embryonen weiterentwickeln können. In der Regel führt die spontane Ausreifung von ES-Zellen in der Zellkultur zunächst zu einem Gemisch verschiedener Zelltypen. Mit Hilfe von Wachstumsfaktoren und Differenzierungsfaktoren oder genetischen Selektionsstrategien ist es möglich, aus diesem Gemisch einzelne Zelltypen anzureichern und zu vermehren. In bestimmten Fällen (neurale Differenzierungen) können ES-Zellen auch ohne vorherige Aggregation zu Embryoidkör- 
Tabelle 1

In-vitro-Differenzierungen von ES-Zellen der Maus

in definierte Zelltypen. (Nach $[3,11])$

Zelltyp
Gefäßsystem/Herz
Endothelzellen
Vaskuläre Glatte Muskelzellen
Kardiomyozyten (Herzmuskelzellen)
Blutbildendes System/Lymphsystem
Hämatopoetische Zellen

Hämatopoetische Zellen

Lymphoide Vorläuferzellen
Mastzellen

Nervensystem

Astrozyten (Makrogliazellen)

Dendritische Zellen

Neurone

Knochen/Muskelsystem

Chondrozyten (Knorpelzellen)

Osteoblasten

Skelettmuskelzellen

Sonstige

Adipozyten (Fettzellen)

Insulin-produzierende Zellen

Keratinozyten
Risau et al. 1988 [45]

Wartenberg et al. 1988 [46]

Yamashita et al 2001 [12]

Drab et al. 1997 [47]

Yamashita et al. 2001 [12]

Doetschman et al. 1985 [48]

Maltsev et al. 1993, $1994[40,41]$

Wobus et al. 1991, $1997[39,49]$

Wiles u. Keller 1991 [50]

Schmitt et al. 1991 [51]

Nakano et al. 1996 [52]

Nishikama et al. 1998 [53]

Potocnik et al. 1994 [54]

Tsai et al. 2000 [55]

Fraichard et al. 1995 [56]

Fairchild et al. 2000 [57]

Bain et al. 1995 [58]

Strübing et al. 1995 [59]

Dinsmore et al. 1996 [31]

Lee et al. 2000 [13]

Rolletschek et al [14]

Brüstle et al. 1999 [29]

Liu et al. 2000 [60]

Kramer et al. 2000 [61]

Buttery et al.2001 [62]

Rohwedel et al. 1994 [63]

Dani et al. 1997 [64]

Soria et al. 2000 [32]

Lumelsky et al. 2001 [15]

Bagutti et al. 1996 [65]

Yamashita et al. 2001 [12] von ES-Zellen wurde unlängst von der Arbeitsgruppe um Shin-Ichi Nishikawa demonstriert [12]. Ihr gelang es, ES-Zellen der Maus in vitro über Zwischenstufen (sog. Vorläuferzellen) in Endothelzellen und andere Gefäßzellen zu differenzieren und diese Zellen in der Kultur zur Ausbildung vaskulärer Strukturen (Blutgefäße) zu veranlassen. In diesen Strukturen wurden zudem erste Blutzellen ausgebildet. Diese Ergebnisse zeigen, dass ES-Zellen nicht nur in verschiedene Zelltypen differenzieren können, sondern die resultierenden Zellen auch in der Lage sind, sich in der Zellkultur spontan zu Geweben zu organisieren.

Unlängst ist es auch gelungen, ESZellen der Maus den komplexen, in mehreren Schritten ablaufenden Prozess der Bildung von Neuronen, die den Neurotransmitter Dopamin (dopaminerge Neuronen) abgeben, in der Zellkultur durchlaufen zu lassen $[13,14]$. Funktionelle Analysen zeigten, dass diese Zellen tatsächlich wie natürliche Neuronen reagieren: sie weisen ein elektrisches Potenzial auf und reagieren auf die Zugabe von Kaliumionen mit der vermehrten Ausschüttung von Dopamin.

\section{„ES-Zellen besitzen die Fähig- keit, in eine Vielzahl spezialisier- ter Körperzellen differenzieren zu können."}

Auch gelang es kürzlich, ES-Zellen über mehrere Zwischenschritte in Inselzellen der Bauchspeicheldrüse zu differenzieren [15]. Diese Zellen reagierten auf $\mathrm{Zu}$ gabe von Glukose in das Medium in dosisabhängiger Weise mit der Produktion von Insulin. Auch zeigen sie die gleichen Reaktionen wie natürliche Inselzellen auf Pharmaka: Agonisten der Insulinproduktion stimulierten die Insulinausschüttung, Antagonisten hemmten sie.

Die drei zuletzt genannten Beispiele machen deutlich, dass es heute möglich ist, aus ES-Zellen der Maus Zellen zu differenzieren, die in ihren funktionellen Eigenschaften den korrespondierenden, spezialisierten Körperzellen entsprechen. Diese Beispiele zeigen auch, dass ES-Zellen während ihrer In-vitroDifferenzierung in einem zeitlich kontrollierten Muster gewebespezifische Gene sowie Proteine exprimieren und sich über definierte zelluläre Zwischenstufen (Vorläuferzellen) in die ausdiffe- pern in der Zellkultur effizient in verschiedene Körperzellen entwickelt werden $[3,10,11]$.

Durch diese Manipulation der Wachstumsbedingungen kultivierter muriner ES-Zellen ist in den vergangenen Jahren die Differenzierung von ESZellen der Maus in eine Reihe von Zellen gelungen (Tabelle 1). Hierzu zählen z. B.
Herzmuskelzellen, Skelettmuskelzellen, Nerven- und Gliazellen, Epithelzellen, Fettzellen, blutbildende (hämatopoetische) Zellen, Insulin-bildende Zellen, Endothelzellen, vaskuläre glatte Muskelzellen, Knorpelzellen, dendritische Zellen, Mastzellen und Osteoblasten.

Ein besonders eindrucksvolles Beispiel für das Differenzierungspotenzial 
renzierten Zellen entwickeln. ES-Zellen der Maus rekapitulieren in der Zellkultur also weitgehend das natürliche Entwicklungsprogramm eines Zelltyps im Organismus.

Diese Ergebnisse sind vielversprechend. Abschließend sei allerdings darauf hingewiesen, dass bis heute die den Differenzierungen in definierte Zelltypen zu Grunde liegenden molekularen Mechanismen in keinem Fall eindeutig geklärt sind. Das Wissen hierüber ist jedoch Voraussetzung, um in Zukunft Differenzierungsprozesse sehr gezielt steuern zu können. Murine ES-Zellen bieten hier ein gutes Modellsystem.

\section{In-vivo-Differenzierungspotenzial muriner ES-Zellen}

Auch in vivo, das heißt im Organismus, können murine ES-Zellen Körperzellen aller drei Keimblätter (Ektoderm, Endoderm, Mesoderm) bilden: Überträgt man ES-Zellen in frühe Embryonen der Maus (Blastozysten), nehmen sie an der Embryonalentwicklung teil und bilden Zellen aller Gewebe, einschließlich der Keimzellen. Diese Eigenschaft der ESZellen hat man sich in der Grundlagenforschung $\mathrm{zu}$ Nutze gemacht. So ist es z. B. möglich, in kultivierten ES-Zellen definierte Gene zu inaktivieren. Werden diese veränderten ES-Zellen anschlieBend in die Blastozyste einer Maus eingebracht und diese wiederum in den Uterus eines Tieres zur Weiterentwicklung übertragen, lässt sich die Funktion des inaktivierten Genes für die Embryonalentwicklung oder für ein Krankheitsgeschehen sehr gut studieren: Die resultierenden Mäuse („Knock-out“-Mäuse) werden Veränderungen in definierten Organen tragen, die wiederum Rückschlüsse auf die Funktion des inaktivierten Genes zulassen. Im Kapitel „In-vivoAnalyse embryonaler Entwicklungsvorgänge und Krankheitsprozesse" werden zwei diesbezügliche Beispiele näher vorgestellt.

\section{Molekulare Eigenschaften muriner ES-Zellen}

Weitere wichtige Merkmale von ES-Zellen finden sich auf molekularer Ebene. ES-Zellen exprimieren z. B. das so genannte Oct-4-Gen. Die Expression dieses Genes, das heißt die Anwesenheit des korrespondierenden Oct-4-Proteins in den Zellen, ist ein Marker für den undifferenzierten und toti- bzw. pluripotenten Zustand von Zellen. Das Protein findet sich sowohl in der Mauszygote als auch in der Inneren Zellmasse des Blastozysten sowie in den kultivierten ES-Zelllinien. Es wird nicht in den Trophoblastzellen von Blastozysten oder in anderen differenzierten Zellen exprimiert [16].

Das Oct-4-Protein ist ein Transkriptionsfaktor, also ein Protein, das an DNA bindet und verschiedene Gene aktivieren oder inaktivieren kann. Bis heute sind etwa acht Gene bekannt, die durch Oct-4 reguliert werden. Durch die Anwesenheit des Oct-4-Proteins und seinen Einfluss auf diese Gene wird bewirkt, dass die ES-Zellen in einem undifferenzierten Zustand verbleiben. Wird Oct-4 in ES-Zellen nicht mehr exprimiert oder aber überexprimiert, differenzieren diese sofort. Die balancierte Expression des Proteins ist also unerlässlich für die Aufrechterhaltung des pluripotenten und undifferenzierten Zustandes von ES-Zelllinien der Maus.

Zusätzlich kennt man auf molekularer Ebene inzwischen eine Reihe weiterer Marker auf der Oberfläche von ESund EG-Zellen der Maus, die sie als undifferenzierte Zellen kennzeichnen. Hierzu zählt das Oberflächenantigen SSEA-1 (stadienspezifisches embryonales Antigen) sowie das Enzym alkalische Phosphatase. Es hat sich gezeigt, dass sich murine ES-Zellen in Hinblick auf die Expression von Oberflächenantigenen von ES-Zelllinien anderer Herkunft (Affe, Mensch) unterscheiden. ES-Zellen der Maus exprimieren Antigen-Epitope, die sich in humanen Zellen nicht finden und umgekehrt.

Weiterhin zeigen ES-Zellen der Maus eine hohe Telomeraseaktivität. In differenzierten Zellen verkürzen sich die Enden der Chromosomen (Telomere) mit jeder Zellteilung, was zur Folge hat, dass die Zellen nur eine begrenzte Lebensdauer besitzen. Das Enzym Telomerase wirkt dieser Verkürzung entgegen, das heißt, eine hohe Telomeraseaktivität verzögert die Alterung der Zellen und erlaubt es ihnen, zahlreiche Zellteilungen zu durchlaufen. Auch zeigen ES-Zellen einen ungewöhnlichen Zellzyklus. Anders als differenzierte Zellen befinden sie sich überwiegend in der so genannten S-Phase des Zellzyklus und benötigen keinen externen Stimulus, um die Vermehrung (Replikation) ihrer
DNA und somit die Zellteilung zu initiieren. Ungewöhnlich ist auch, dass in ESZellen keine Inaktivierung des X-Chromosoms erfolgt. In differenzierten somatischen Zellen weiblicher Säuger wird stets eines der beiden vorliegenden $\mathrm{X}$-Chromosomen permanent inaktiviert. In ES-Zellen sind beide funktionsfähig. Die Ursache hierfür ist unbekannt.

\section{Eigenschaften von EG-Zellen der Maus}

EG-Zellen der Maus verfügen in ähnlicher Weise wie ES-Zellen über ein hohes Proliferations- und Entwicklungspotenzial. In der Zellkultur differenzieren EGZellen wie ES-Zellen in eine Vielzahl spezialisierter Zelltypen [17]. Sie exprimieren auch die oben genannten Markergene Oct-4 und die erwähnten Oberflächenproteine und sind damit als undifferenzierte, pluripotente Stammzellen gekennzeichnet.

Dennoch bestehen Unterschiede in der Genregulation und daraus abgeleitet im In-vivo-Entwicklungspotenzial dieser Stammzellen. Neuere Arbeiten lassen daher Zweifel aufkommen, dass EG-Zellen und ES-Zellen gleichwertig sind. Während der Embryonalentwicklung eines Organismus werden im Verlaufe der Keimzellbildung einzelne Gene gemäß ihres elterlichen Ursprunges (väterliche oder mütterliche Gene) selektiv inaktiviert, ein Prozess, der Imprinting genannt wird. Das Imprinting ist in primordialen Keimzellen und damit auch in EG-Zelllinien aufgehoben. Bei Verwendung derartiger „Imprintfreier" EG-Zellen, z. B. zur Erzeugung von chimären Mäusen, kann es während ihrer Differenzierung im Organismus zu Störungen kommen: Die von den EGZellen abstammenden Gewebe dieser Tiere entwickelten sich nicht normal, die Embryonen waren größer und zeigten Skelettanomalien. EG-Zellen der Maus zeigen also im Vergleich zu ES-Zellen der Maus in vivo ein eingeschränktes Entwicklungspotenzial $[18,19,20]$.

Derzeit lässt sich auch noch keine Aussage darüber machen, ob murine EG-Zellen, die in der Kultur in spezielle Gewebe differenziert wurden, wie differenzierte ES-Zellen, in die Maus übertragen und dort zur Geweberegeneration eingesetzt werden können. Diesbezügliche tierexperimentelle Untersuchungen stehen noch aus. Es kann also gegenwärtig nicht eingeschätzt werden, 
ob und inwieweit sich der Imprintingstatus muriner EG-Zellen auf ihre Differenzierungsfähigkeit und auf das Verhalten der aus ihnen hervorgehenden somatischen Zellen im Organismus nach Transplantation auswirkt. Die folgenden Ausführungen konzentrieren sich daher auf die Darstellung der mit ES-Zellen der Maus gewonnenen tierexperimentellen Ergebnisse.

\section{Anwendung und Einsatz von ES-Zellen der Maus}

\section{In-vivo-Analyse embryonaler Entwicklungsvorgänge und Krankheitsprozesse}

Wie bereits oben angemerkt, ist es möglich, ES-Zelllinien der Maus in der Zellkultur mit Hilfe der Technologie des „Gene targeting“ [21] genetisch zu verändern: Durch homologe Rekombination werden definierte Gene in den ESZellen gezielt inaktiviert. Nach Injektion dieser genetisch veränderten ES-Zellen in Empfänger-Blastozysten von Mäusen können sie in die Innere Zellmasse (ICM) integrieren und im Verlauf der Embryonalentwicklung verschiedene Gewebe des Organismus bilden. Die resultierenden Mäuse werden dann in ihren Organen Zellen tragen, die das gezielt inaktivierte Gen nicht mehr exprimieren und es kann dementsprechend in diesen Tieren (Knock-out-Mäuse) zu embryonalen Fehlentwicklungen und/ oder zu Fehlfunktionen bestimmter Organe kommen. Die beobachteten Funktionsverluste („loss of function“) lassen wiederum Rückschlüsse auf die Funktion des untersuchten Genes für die Embryonalentwicklung oder für die Ausprägung einer Krankheit zu.

\section{„Mit Hilfe von ES-Zellen lassen sich komplexe Entwicklungs- vorgänge und Krankheitspro- zesse studieren."}

Beispiele aus dem Bereich der Entwicklungsbiologie bzw. der biomedizinischen Forschung sind Mäuse, die über ES-Zellen eingeführte Defekte z. B. in den so genannten Pax-Genen oder dem Prionprotein-Gen tragen. „Knock-out“ Mäuse, in denen Mitglieder der PaxGenfamilie inaktiviert wurden, machen deutlich, dass diese Gene an der Muster- bildung im Nervensystem der Wirbeltiere beteiligt sind. $\mathrm{Zu}$ dieser Familie gehören neun Gene (Pax1 - Pax 9). Pax-Gene kodieren für Transkriptionsfaktoren, die unmittelbar an die DNA binden und somit die Expression weiterer Gene regulieren. Durch gezielte Mutationen in einzelnen oder mehreren Pax-Genen kommt es zu Störungen in der Ausbildung und Organisation des Vorderhirns (bei Inaktivierung von Pax 6), des Rückenmarks (bei Inaktivierung von Pax 3, Pax 7) oder zu einer fehlerhaften Organisation der Grenze zwischen Mittel- und Rautenhirn (bei Inaktivierung von Pax 2, Pax 5, Pax 8). Die Analyse der Knock-out-Tiere hat somit gezeigt, dass Pax-Proteine essentiell für die Koordination der frühen embryonalen Musterbildung entlang der sich entwickelnden Neuralachse sind. Mutationen in diesen Genen führen zu Fehlentwicklungen (z. B. [22]).

An Knock-out-Mäusen, die Mutationen in dem Gen tragen, das für das Prionprotein kodiert, konnte die Rolle dieses Proteins für die Ausprägung übertragbarer spongiformer Enzephalopathien (TSE, Prionenerkrankungen) studiert werden. Nach der „Proteinonly“-Hypothese induziert ein infektiöses Prionprotein im normalen zellulären Prionprotein eine Konformationsänderung, wodurch Letzteres ebenfalls infektiöse und pathogene Eigenschaften erlangt. Nach Inaktivierung des zellulären, normalen Priongens mit Hilfe der homologen Rekombination in ES-Zellen sind die resultierenden Knock-outMäuse resistent gegenüber einer Infektion mit dem pathogenen Agens. Ursache hierfür ist die fehlende Expression des normalen, zellulären Prionproteins in den Tieren. Es liegt also kein Protein vor, das in eine pathogene Form umgewandelt werden kann. Nach Transplantation embryonalen Hirngewebes normaler Mäuse, die das zelluläre Prionprotein exprimieren, in das Gehirn der Knockout-Tiere zeigt das übertragene Gewebe eine Anfälligkeit gegenüber dem infektiösen Prionprotein. Die Erzeugung und Analyse der Knock-out-Mäuse erlaubte somit Einblicke in den Pathogenitätsmechanismus, der den Prionerkrankungen zu Grunde liegt [23].

Mittlerweile liegen mehrere hundert Knock-out-Mausstämme mit Defekten in definierten Genen vor. Die Analyse dieser Tiere hat unser Wissen über die embryonalen Entwicklungsprozesse bei Säugern sowie über die Beteiligung von Genen an bestimmten Krankheitsprozessen erheblich erweitert. Knock-out-Mäuse sind unerlässliche Modellsysteme für die Grundlagenforschung und biomedizinische Forschung.

\section{In-vitro-Analyse embryonaler Entwicklungsvorgänge und Krankheitsprozesse}

ES-Zellen, in denen ein bestimmtes Gen nach homologer Rekombination inaktiviert wurde, können in ihrer Differenzierungsfähigkeit auch in vitro untersucht werden. Diese Strategie ist dann eine geeignete Alternative zu den oben dargelegten Experimenten mit Knock-outMäusen, wenn die Inaktivierung der Genfunktion in den ES-Zellen zu gravierenden Störungen der Embryonalentwicklung führt und die resultierenden Embryonen daher in einem sehr frühen Entwicklungsstadium absterben würden. Dies ist z. B. bei einer Mutation im Gen, das für das Protein $\beta_{1}$-Integrin kodiert, der Fall. Integrine vermitteln die Interaktion von Zellen mit extrazellulären Matrixproteinen, und ihr Verlust führt zum Absterben der Embryonen kurz nach der Implantation, das heißt, man kann in diesen Tieren die genaue Auswirkung der Inaktivierung des Genes mit herkömmlichen Methoden nicht studieren [24].

Inaktiviert man nun das $\beta_{1}$-Integrin-Gen in ES-Zellen der Maus und differenziert diese Zellen anschließend in vitro in Herz-, Skelettmuskel- und Nervenzellen, kann man den Einfluss dieser Mutation auf das normale Entwicklungsprogramm der Zellen analysieren. Es zeigte sich, dass das Fehlen des $\beta_{1}$-Integrins in den ES-Zellen zur Folge hatte, dass das Programm der kardiogenen, myogenen und neuronalen Entwicklung gestört ist $[25,26]$. Im Hinblick auf die Herzzelldifferenzierung bedeutete dies: Während ES-Zellen, die ein funktionsfähiges $ß_{1}$-Integrin tragen, in ca. 50\% Ventrikelzellen, 40\% atriale Zellen und 10\% Schrittmacherzellen differenzierten, war in den Mutantenzellen der Beginn der Herzzellentwicklung verzögert, und ventrikuläre und atriale Zellen wurden nur vorübergehend und in geringer Anzahl nachgewiesen. Dagegen wurden in terminalen Entwicklungsstadien 
Tabelle 2

Transplantationen von somatischen Zellen, die aus ES-Zellen der Maus differenziert wurden, in Tiermodelle (Maus oder Ratte)

\begin{tabular}{lll} 
Zelltyp & Transplantation in & Referenz \\
\hline Kardiomyozyten & $\begin{array}{l}\text { Ventrikuläres Myokard dystrophischer } \\
\text { Mäuse }\end{array}$ & Klug et al. 1996 [28] \\
GABAerge Neuronen & $\begin{array}{l}\text { Striatium der Ratte } \\
\text { (Chorea-Huntington-Modell) }\end{array}$ & Dinsmore et al. 1996 [31] \\
Neuronale Vorläuferzellen & $\begin{array}{l}\text { Telencephalon der Ratte } \\
\text { Intraventrikulär in Myelin-defiziente }\end{array}$ & Brüstle et al. 1997 [66] \\
Neuronale Vorläuferzellen et al. 1999 [29] & $\begin{array}{l}\text { Ratten (Embryonen) } \\
\text { (Pelizäus-Merzbacher-Modell) }\end{array}$ & \\
& $\begin{array}{l}\text { Ratten mit durchgetrenntem Rückenmark } \\
\text { Neuronale Zellen }\end{array}$ & McDonald et al. 1999 [30] \\
Insulin-produzierende Zellen & $\begin{array}{l}\text { Milz Streptozotocin-behandelter Mäuse } \\
\text { (Diabetes-Modell) }\end{array}$ & Soria et al. 2000 [32]
\end{tabular}

Herzzellen mit defektem Sarkomerapparat und atypischen Schrittmacheraktionspotenzialen gefunden $[25,27]$.

Auch diese Experimente zeigen, dass bereits mit der Untersuchung von in Kultur gehaltenen ES-Zellen komplexe Fragen zur Differenzierung von Zellen und der daran maßgeblich beteiligten Gene bearbeitet werden können.

\section{Einsatz zur Ermittlung des therapeutischen Potenzials differenzierter Stammzellen}

Pluripotenz und nahezu unbegrenzte Vermehrbarkeit der Maus-ES-Zellen machen diese Zellen zu einer idealen Quelle für Zell- und Gewebeersatz. Am Modell muriner ES-Zelllinien ist daher in den letzten Jahren die Frage untersucht worden, ob sich ES-Zellen, die in der Zellkultur differenziert werden, therapeutisch einsetzen lassen.

In Versuchen an Tiermodellen konnte gezeigt werden, dass ES-Zellen tatsächlich eine realistische Möglichkeit für Zellersatztherapien bieten können (Tabelle 2). Bereits 1996 wurden aus ESZellen differenzierte Herzmuskelzellen (Kardiomyozyten) in die Herzkammer von Mäusen transplantiert, wo sie integrierten und noch nach sieben Wochen nachweisbar waren [28]. Weiterhin wurde die Bildung von Myelinscheiden in Myelin-defekten Ratten (Pelizäus-Merzbacher Krankheit) demonstriert [29] und über die Wiederherstellung der motorischen Beweglichkeit von querschnittsgelähmten Ratten nach Trans- plantation von aus murinen ES-Zellen differenzierten Neuronen berichtet [30]. Auch wird intensiv daran gearbeitet, mit Hilfe dopaminerger [13] oder GABAerger Nervenzellen [31], die von ES-Zellen der Maus abgeleitet sind, therapeutische Ansätze zur Behandlung der ParkinsonKrankheit bzw. der Chorea Huntington $\mathrm{zu}$ entwickeln. In weiteren Arbeiten gelang die Differenzierung muriner ESZellen zu Insulin-bildenden Zellen [14, 32] und ihre Transplantation in diabetische Mausmodelle [32].

Die an Tiermodellen erhobenen Befunde machen deutlich, dass in der Verwendung von ES-Zellen als Zell- und Gewebeersatz ein großes therapeutisches Potenzial liegt. Die Frage allerdings, ob sich auch aus humanen ESZellen in ähnlicher Weise spezifische Spenderzellen gewinnen lassen und inwieweit diese nach Transplantation die Funktion defekter Organe oder Gewebe wiederherstellen können, lässt sich gegenwärtig noch nicht eindeutig beantworten. In verschiedenen Laboratorien im Ausland sind daher Forschungsarbeiten an humanen Zelllinien initiiert worden. Hier wird z. B. versucht, standardisierte und praktikable Differenzierungsverfahren zur Gewinnung ausreichender Mengen einer homogenen Population der differenzierten Zellen zu etablieren sowie die Faktoren zu ermitteln, die die gerichtete Differenzierung in definierte Zelltypen und ihre Selektion erlauben. Diese Arbeiten werden durchgeführt, weil Kontaminationen der differenzierten Zellen mit unreifen em- bryonalen Zellen nach Transplantation in den Organismus zur Bildung von Fremdgeweben oder Tumoren (sog. Teratome oder Teratokarzinome, siehe oben) führen können [33]. Ein weiteres Problem ist die Gewebeunverträglichkeit zwischen den differenzierten ESZellen und einem spezifischen Empfängerorganismus. Hier werden sich Wissenschaftler damit befassen, Strategien zu entwickeln, um die immunologischen Barrieren zu überwinden.

\section{Einsatz für toxikologische und pharmakologische Untersuchungen}

Bereits seit mehreren Jahren gibt es Bestrebungen, undifferenzierte embryonale Zellen in vitro zum Nachweis zytotoxischer, embryotoxischer, teratogener (Fehlbildung verursachender), mutagener (erbgutschädigender) und kanzerogener (krebserregender) Substanzen einzusetzen $[34,35,36]$. In diesem $\mathrm{Zu}$ sammenhang ist die Etablierung des embryonalen Stammzelltests zu nennen $[37,38]$. Maus-ES-Zellen wurden bereits in einer EU-Validierungsstudie zum Nachweis embryotoxischer Verbindungen eingesetzt. Mit Hilfe statistischer Verfahren wurde ein Prediktionsmodell entwickelt, das eine große Übereinstimmung zwischen den In-vitro-Daten des ES-Zelltests und den am Versuchstier in vivo gewonnenen Befunden ergab. Der ES-Zelltest erlaubte eine Einteilung der Testchemikalien in drei Klassen, „nicht embryotoxisch“, „schwach embryotoxisch“ und „stark embryotoxisch“. Die Weiterentwicklung des Stammzelltests könnte die Grundlage für die Entwicklung von Screeningprogrammen für embryotoxische/teratogene Substanzen mit humanen ES-/EG-Zelllinien in vitro legen und damit umfangreiche Tierversuche in der Embryotoxikologie ersetzen.

\section{„ES-Zellen der Maus wurden bereits zum Nachweis embryotoxischer Substanzen eingesetzt."}

Auch die Wirkungen von Pharmaka lassen sich direkt an ES-Zellen analysieren. So reagieren aus ES-Zellen der Maus differenzierte Kardiomyozyten in gleicher Weise wie Zellen aus dem Organismus auf herzaktive Pharmaka: Durch Zugabe von kardiotropen Wirkstoffen, wie $\beta$ - 


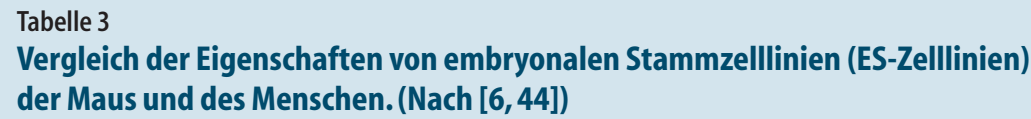

Eigenschaften

Murine ES-Zellen

Humane ES-Zellen

Verhalten in der Zellkultur (in vitro)

Potenzial zu nahezu unbegrenzter

Ja

Wahrscheinlich

Proliferation ohne Verlust des

undifferenzierten Zustandes

Wachstumseigenschaften

Runde, mehrschichtige,

Flache, lockere kompakte Kolonien. Zellaggregate. Können EB bilden Können EB bilden

Differenzierungspotenzial in Zellen aller drei Keimblätter

Feeder-Layer Abhängigkeit

Faktoren, die die Proliferation regulieren

Stabiler euploider Karyotyp

Ja

Ja/oder LIF bzw. andere IL-6 Zytokine

LIF oder andere IL-6 Zytokine Feeder-Layer + Serum; Feeder-Layer + Serumfreies Medium + bFGF

Verhalten in vivo

Differenzierungspotential in alle drei

Keimblätter, d. h.Chimärenbildung nach Übertragung in Blastozysten

Keimbahntransmission

Teratombildung im Mausmodell

Ja

Unbekannt

Markerproteine

SSEA-1

SSEA-3

SSEA-4

TRA-1-60

TRA-1-81

Alkalische Phosphatase

Sonstiges

\section{Kurze G1-Phase des Zellzyklus}

Hohes Kern-Zytoplasmaverhältnis

ES Embryonale Stammzellen; SSEA Stage specific embryonic antigen (stadiumspezifisches embryonales Antigen); TRA Tumor rejection antigen-1; LIF Leukemia inhibitory factor (Leukämie inhibierender Faktor); bFGF Basic fibroblast growth factor (Fibroblasten-Wachstumsfaktor); EB Embryoid body (EmbryoidKörper); IL-6 Interleukin 6.

Adrenozeptor-Agonisten oder dem $\mathrm{Ca}^{2+}$-Kanal-Öffner BayK8644 einerseits, oder $\mathrm{Ca}^{2+}$-Kanal-Blockern und muscarinen Acetylcholinrezeptor-Agonisten andererseits, werden positiv chronotrope bzw. negativ chronotrope Reaktionen ausgelöst [39, 40, 41, 42, 43]. Daraus kann abgeleitet werden, dass die Aktivität von herzzellspezifischen Rezeptoren sowie die zu Grunde liegenden intrazellulären
Signalwege in aus ES-Zellen differenzierten Kardiomyozyten in gleicher Weise reguliert werden wie in Zellen, die sich im lebenden Organismus entwickelt haben.

Die beispielhaft dargestellten, an murinen ES-Zellen erhobenen Befunde zeigen, dass sich ES-Zellen für pharmakologische und toxikologische Untersuchungen eignen können.

\section{Unterschied zwischen ES-Zellen der Maus und des Menschen}

Untersuchungen im Ausland haben gezeigt, dass sich die z. Z. vorliegenden ESZelllinien des Menschen in einigen Eigenschaften von den vorhandenen ESZelllinien der Maus unterscheiden [44]. In Tabelle 3 sind diese Unterschiede aufgeführt. Sie zeigen, dass murine und humane ES-Zellen sich sowohl in ihrem Verhalten in der Zellkultur als auch auf molekularer Ebene unterscheiden.

Humane ES-Zellen können z. B. nur in Anwesenheit von „Feeder-Layern“ ihren undifferenzierten Zustand in der Zellkultur bewahren. Anders als murine ES-Zellen lässt sich dieser „Feeder Layer“ nicht durch Differenzierungshemmfaktoren (Zytokine der Interleukin-6-Familie, wie z. B. LIF) ersetzen, da die humanen Zellen auf diese nicht reagieren. Die Gründe hierfür sind unbekannt. Zudem exprimieren murine ES-Zellen Gene, die in ES-Zellen des Menschen offenbar nicht aktiv sind und umgekehrt. So findet sich zwar in den Zellen der Maus, nicht aber in den menschlichen ES-Zellen, das für den undifferenzierten Zustand charakteristische stadienspezifische embryonale Antigen-Epitop SSEA-1. Umgekehrt exprimieren die humanen Zellen die Antigene SSEA-3 und SSEA-4, die wiederum in den ES-Zellen der Maus fehlen $[6,7]$. Auch andere Proteine, die als Marker für den undifferenzierten Zustand embryonaler Stammzellen gelten, finden sich nur in menschlichen aber nicht in murinen ES-Zellen (z.B.TRA1-60, TRA1-81). Hingegen werden der Transkriptionsfaktor Oct-4 und das Enzym alkalische Phosphatase in beiden Zelltypen exprimiert.

Bisher lassen sich diese Unterschiede zwischen ES-Zellen des Menschen und der Maus nur beschreiben, aber nicht erklären. Die biologische Bedeutung dieser Unterschiede ist noch unklar. Sie könnten jedoch die Ursache für das unterschiedliche Wachstumsverhalten der Zellen sein: Undifferenzierte humane ES-Zellen tendieren dazu, in der Zellkultur in relativ flachen, lockeren Zellverbänden (Kolonien) zu wachsen, während ES-Zellen der Maus eher kompakte, aus mehreren Zelllagen bestehende Kolonien bilden. Die molekularen und morphologischen Unterschiede können aber auch bedeuten, dass sich die etablierten humanen und murinen ES-Zelllinien in unterschiedlichen Entwicklungsstadien befinden. 


\section{Fazit}

Die Arbeit mit ES-Zellen der Maus hat uns zahlreiche Erkenntnisse über die grundlegenden Eigenschaften und das Potenzial embryonaler Stammzellen gebracht. Wir wissen heute, dass diese Zellen sowohl in der Grundlagenforschung als auch in der medizinischen Forschung zur Aufklärung komplizierter Entwicklungsvorgänge und zur Aufklärung von Krankheitsprozessen unersetzliche Werkzeuge darstellen.Zudem hat der Umgang mit ihnen gezeigt, dass embryonalen Stammzellen ein groBes therapeutisches Potenzial innewohnt und sie auch zu analytischen Zwecken eingesetzt werden können. Viele Erkenntnisse, die an ES-Zellen der Maus gewonnen wurden und werden, lassen sich mit Sicherheit auch auf menschliche ES-Zellen übertragen. Doch bleiben die bereits beschriebenen Unterschiede zwischen diesen Zellen zu bedenken. Diese Unterschiede legen die Vermutung nahe, dass nicht alle Fragen zu Eigenschaften und Verhaltensweisen humaner ES-Zellen am Modellsystem der murinen Zellen analysiert werden können. Vor allem in Australien, Israel und den USA werden daher Untersuchungen direkt an etablierten Zelllinien menschlicher embryonaler Stammzellen vorgenommen, um die Möglichkeiten und Grenzen für ihren therapeutischen Einsatz zu ermitteln.

\section{Literatur}

1. Evans MJ, Kaufmann MH (1981) Establishment in culture of pluripotential stem cells from mouse embryos. Nature 291:154-156

2. Martin G (1981) Isolation of a pluripotent cell line from early mouse embryos cultured in medium conditioned by teratocarcinoma cells. Proc Nat Acad Sci USA 78:7634-7638

3. Smith AG (2001) Embryo-derived stem cells: of mice and men. Annu Rev Cell Dev Biol 17:435-462

4. Thomson JA, Kalishman J, Golos TG, Durning M, Harris CP, Becker RA, Hearn JP (1995) Isolation of primate embryonic stem cell line. Proc Natl Acad Sci USA 92:7844-7848

5. Thomson JA, Marshall VS (1998) Primate embryonic stem cells. Curr Top Dev Biol 38:133-165

6. Thomson JA, Itskovitz-Eldor J, Shapiro SS, Waknitz MA, Swiergiel JJ, Marshall VS, Jones JM (1998) Embryonic stem cell lines derived from human blastocysts. Science 282:1145-1147

7. Reubinoff BE, Pera MF, Fong $C Y$, Trouson A, Bongso A (2000) Embryonic stem cell lines from human blastocysts: somatic differentiation in vitro. Nat Biotechnol 18:399-404
8. Matsui Y, Zsebo K, Hogan BL (1992) Derivation of pluripotent embryonic stem cells from murine primordial germ cells in culture. Cell 70:841-847

9. Resnick JL, Bixler LS, Cheng L, Donovan PJ (1992) Long term proliferation of mouse primordial germ cells in culture. Nature 359:550-551

10. Marshak DR, Gottlieb D, Gardner RL (2001) Introduction: Stem Cell Biology. In: Marshak DR, Gardner RL, Gottlieb D (eds) Stem cell biology. Cold Spring Harbor Laboratory Press, Cold Spring Harbor New York

11. National Institute of Health (2001) Stem cells: scientific progress and future research directions.http://www.nih.gov/news/stemcell/ scireport.htm

12. Yamashita J, Itoh H, Hirashima M et al. (2000): Flk1-positive cells derived from embryonic stem cells serve as vascular progenitors. Nature 408:92-96

13. Lee SH, Lumelsky N, Studer L, Auerbach JM, McKay RD (2000) Efficient generation of midbrain and hindbrain neurons from mouse embryonic stem cells. Nat Biotechnol 18:675-679

14. Rolletschek A, Chang H, Guan K, Czyz J, Meyer M, Wobus AM (2001) Differentiation of embryonic stem cell-derived dopaminergic neurons is enhanced by survival-promoting factors. Mech Dev 105:93-104

15. Lumelsky N, Blondel $\mathrm{O}$, Laeng P, Velasco I, Ravin R, McKay R (2001) Differentation of embryonic stem cells to insuline-secreting structures similiar to pancreatic islets. Science 292:1389-1394

16. Schöler $H$, Dressler R, Balling R, Rohdewohld $H$, Gruss P (1990) Oct4: a germline specific transcription factor mapping to the mouse t-complex. EMBO J 9:2185-2195

17. Rohwedel J, Sehlmeyer U, Shan J, Meister A, Wobus AM (1996) Primordial germ cell-derived mouse embryonic germ (EG) cells in vitro resemble undifferentiated stem cells with respect to differentiation capacity and cell cycle distribution. Cell Biol Int 20:279-587

18. Lefebvre L, Viville S, Barton SC, Ishino F, Keverne EB, Surani MA (1998) Abnormal maternal behaviour and growth retardation associated with loss of the imprinted gene Mest. Nat Genet 20:108-109

19. Surani MA (1999) Reprogramming a somatic nucleus by trans-modification activity in germ cells. Semin Cell Dev Biol 10:273-277

20. Kato Y, Rideout WM 3rd, Hilton K, Barton SC, Tsunoda Y, Surani MA (1999) Developmental potential of mouse primordial germ cells. Development 126:1823-1832

21. Thomas KR, Capecchi MR (1987) Site-directed mutagenesis by gene targeting in mouse embryo-derived stem cells. Cell 51:503-512

22. Schwarz M, Alvarez-Bolado G, Urbanek P, Busslinger M, Gruss P (1997) Conserved biological function between $\operatorname{Pax} 2$ and $\operatorname{Pax} 5$ in midbrain and cerebellum development: evidence from targeted mutations. Proc Natl Acad Sci USA 94:14518-14523
23. Brandner S, Isenmann S, Raeber A et al. (1996) Normal host prion protein necessary for scrapie-induced neurotoxicity. Nature 379:339-343

24. Fässler R, Meyer M (1995) Consequences of lack of $\beta_{1}$ integrin gene expression in mice. Genes Dev 9:1896-1908

25. Fässler R, Rohwedel J, Maltsev V et al. (1996) Differentiation and integrity of cardiac muscle cells are impaired in the absence of $\beta_{1}$ integrin.J Cell Sci 109:2989-2999

26. Rohwedel J, Guan K, Zuschratter W et al. (1998) Loss of $\beta_{1}$ integrin function results in a retardation of myogenic, but an acceleration of neuronal differentiation of embryonic stem (ES) cells in vitro. Dev Biol 201:167-184

27. Guan K, Fürst DO, Wobus AM (1999) Modulation of sarcomere organization during embryonic stem cell-derived cardiomyocyte differentiation. Eur J Cell Biol 78:813-823

28. Klug MG, Soonpa MH, Koh GY, Field L (1996) Genetically selected cardiomyocytes from differentiating embryonic stem cells form stable intracardiac grafts.J Clin Invest 98:216-224

29. Brüstle O, Jones NK, Learish RD, Karrami K, Choudhary K, Wiestler OD, Duncan ID, McKay RDG (1999) Embryonic stem cellderived glial precursors: a source of myelinating transplants. Science 285:754-765

30. McDonald JW, Liu XZ, Qu Y, Mickey SK, Turetsky D, Gottlieb DI, Choi DW (1999) Transplanted embryonic stem cells survive, differentiate and promote recovery in injured rat spinal cord. Nat Med 5:1410-1413

31. Dinsmore J, Ratcliff J, Deacon T, Pakazaban $P_{,}$ Jacoby D, Galpern D (1996) Embryonic stem cells differentiated in vitro as a novel source of cells for transplantation. Cell Transplant 5:131-143

32. Soria B, Roche E, Berna E, Leon-Quinto T, Reig JA, Martin F (2000) Insulin-secreting cells derived from embryonic stem cells normalize glycemia in streptozotocin-induced diabetic mice. Diabetes 49:1-6

33. Stevens LC (1983) The origin and development of testicular, ovarian, and embryo-derived teratomas. In: Silver LM, Martin, GR, Strickland S (eds) Teratocarcinoma stem cells. Cold Spring Harbor Laboratory Press, Cold Spring Harbor New York, pp 23-36

34. Laschinski G, Vogel R, Spielmann H (1991) Cytotoxicity test using blastocyst-derived euploid embryonal stem cells: a new approach to in vitro teratogenesis screening. Reprod Toxicol 5:57-64

35. Sehlmeyer U, Meister A, Beisker W, Wobus AM (1996) Low mutagenic effects of mitomycin C in undifferentiated embryonic P19 cells are correlated with efficient cell cycle control. Mut Res 354:103-112

36. Sehlmeyer U, Rohwedel J, Wobus AM (1996) Primordial germ cell-derived embryonic germ cells of the mouse - in vitro model for cytotoxicity studies with chemical mutagens. In Vitro Toxicol 10:755-763 
37. Spielmann H, Pohl I, Döring B, Liebsch M, Moldenhauer F (1997) The embryonic stem cell test, an in vitro embryotoxicity test using two permanent mouse cell lines: $3 \mathrm{~T} 3$ fibroblasts and embryonic stem cells. In Vitro Toxicol 10:119-127

38. Scholz G, Pohl I, Genschow E, Klemm M, Spielmann H (1999) Embryotoxicity screening using embryonic stem cells in vitro: correlation to in vivo teratogenicity. Cells Tissues Organs 165:203-211

39. Wobus AM, Wallukat $\mathrm{G}$, Hescheler J (1991) Pluripotent mouse embryonic stem cells are able to differentiate into cardiomyocytes expressing chronotropic responses to adrenergic and cholinergic agents and $\mathrm{Ca}^{2+}$ channel blockers. Differentiation 48:173-182

40. Maltsev VA, Rohwedel J, Hescheler J, Wobus AM (1993) Embryonic stem cells differentiate in vitro into cardiomyocytes representing sinusnodal, atrial and ventricular cell types. Mech Dev 44:41-50

41. Maltsev VA, Wobus AM, Rohwedel J, Bader M, Hescheler J (1994) Cardiomyocytes differentiated in vitro from embryonic stem cells developmentally express cardiac-specific genes and ionic currents. Circ Res 75:233-244

42. Maltsev VA, Ji GJ, Wobus AM, Fleischmann B, Hescheler J (1999) Establishment of $\beta$ adrenergic modulation of L-type $\mathrm{Ca}^{2+}$ current in the early stages of cardiomyocyte development. Circ Res 84:136-145

43. Pich U, Pütz D, Wobus AM (1997) Screeningverfahren zur Messung chronotroper Effekte an Herzzellen. BIOforum 20:536-540

44. Pera MF, Reubinoff B, Trouson A (2000) Human embryonic stem cells.J Cell Sci 113:5-10

45. Risau W, Sariola H, Zerwes HG, Sasse J, Ekblom P, Kemler R, Doetschman T (1988) Vasculogenesis and angiogenesis in embryonic-stem-cell-derived embryoid bodies. Development 102:471-478

46. Wartenberg M, Günther J, Hescheler J, Sauer H (1998) The embryoid body as a novel in vitro assay system for antiangiogenic agents. Laborat Invest 78:1301
47. Drab M, Haller H, Bychkow R et al. (1997) From totipotent embryonic stem cells to spontaneously contracting vascular smooth muscle cells: a retinoic acid and db-cAMP in vitro differentiation model. FASEB J 11:905-915

48. Doetschman T, Eistetter H, Katz M, Schmitt W, Kemler R (1985) The in vitro development of blastocyst-derived embryonic stem cell lines: formation of visceral yolk sac, blood islands and myocardium.J Embryol Exp Morph 87:27-45

49. Wobus AM, Guan K, Jin S et al. (1997) Retinoic acid accelerates embryonic stem cell-derived cardiac differentiation and enhances development of ventricular cardiomyocytes. J Mol Cell Cardiol 29:1525-1539

50. Wiles MV, Keller G (1991) Multiple hematopoietic lineages develop from embryonic stem (ES) cells in culture. Development 111:259-267

51. Schmitt RM, Bruyns E, Snodgrass HR (1991) Hematopoietic development of embryonic stem cells in vitro: cytokine and receptor gene expression. Genes Dev 5:728-740

52. Nakano T, Kodama H, Honjo $\mathrm{T}$ (1996) In vitro development of primitive and definitive erythrocytes from different precursors. Science 272:722-724

53. Nishikawa SI, Nishikawa S, Hirashima M, Matsuyoshi N, Kodama H (1998) Progressive lineage analysis by cell sorting and culture identifies FLK1(+)VE-cadherin(+) cells at a diverging point of endothelial and hemopoietic lineages. Development 125:1747-1757

54. Potocnik A, Nielsen PJ, Eichmann K (1994) In vitro generation of lymphoid precursors from embryonic stem cells. EMBO J 13:5274-5283

55. Tsai M, Wedemeyer J, Ganiatsas S, Tam SY, Zon LI, Galli SJ (2000) In vivo immunological function of mast cells derived from embryonic stem cells: an approach for the rapid analysis of even embryonic lethal mutations in adult mice in vivo. Proc Natl Acad Sci USA 97:9186-9190

56. Fraichard A, Chassande O, Bilbaut G, Dehay C, Savatier P, Samarut J (1995) In vitro differentiation of embryonic stem cells into glial cells and functional neurons.J Cell Sci 108:3181-3188

57. Fairchild PJ, Brook FA, Gardner RL et al. (2000) Directed differentiation of dendritic cells from mouse embryonic stem cells. Curr Biol 10:1515-1518
58. Bain G, Kitchens D, Yao M, Huettner JE, Gottlieb DI (1995) Embryonic stem cells express neuronal properties in vitro. Dev Biol 168:342-357

59. Strübing $C$, Ahnert-Hilger $G$, Jin $S$, Wiedenmann B, Hescheler J, Wobus AM (1995) Differentiation of pluripotent embryonic stem cells into the neuronal lineage in vitro gives rise to mature inhibitory and excitatory neurons. Mech Dev 53:275-287

60. Liu S, Qu Y, Stewart TJ, Howard MJ, Chakrabortty S, Holekamp TF, MCDonald JW (2000) Embryonic stem cells differentiate into oligodendrocytes and myelinate in culture and after spinal cord transplantation. Proc Natl Acad Sci USA 97:6126-6131

61. Kramer J, Hegert C, Guan K, Wobus AM, Müller PK, Rohwedel J (2000) Embryonic stem cell-derived chondrogenic differentiation in vitro: activation by BMP-2 and BMP-4. Mech Dev 92:193-205

62. Buttery LD, Bourne S, Xynos JD et al. (2001) Differentiation of osteoblasts and in vitro bone formation from murine embryonic stem cells. Tissue Eng 7:89-99

63. Rohwedel J, Maltsev V, Bober E, Arnold HH, Hescheler J, Wobus AM (1994) Muscle cell differentiation of embryonic stem cells reflects myogenesis in vivo: Developmentally regulated expression of myogenic determination genes and functional expression of ionic currents. Dev Biol 164:87-101

64. Dani C, Smith AG, Dessolin S et al. (1997) Differentiation of embryonic stem cells into adipocytes in vitro.J Cell Sci 110:1279-1285

65. Bagutti C, Wobus AM, Fässler R, Watt F (1996) Differentiation of embryonal stem cells into keratinocytes: Comparison of wild-type and $\beta_{1}$ integrin-deficient cells. Dev Biol 179:184-196

66. Brüstle 0, Spiro CA, Karram K, Choudhary K, Okabe S, McKay RDG (1997) In vitro generated neural precursors participate in mammalian development. Proc Natl Acad Sci USA 94:14809-14814 